\title{
Effect of Maximal Medical Therapy on Refractoriness of Unstable Angina Pectoris
}

\author{
David W. Grambow, MD, and Eric J. Topol, MD
}

\begin{abstract}
A group of 125 patients with unstable angina were studied over a 5-year period to define the incidence of refractory unstable angina in the current era of 5-drug medical therapy with intravenous heparin, aspirin, nitrates, calcium antagonists and $\beta$ blockers. All patients had $>\mathbf{2 0}$ minutes of chest pain at rest with reversible electrocardiographic changes occurring in the absence of myocardial infarction. Patients were considered refractory only if chest pain continued despite treatment with maximal 5-drug therapy.
\end{abstract}

At the time of transfer to the center, 65 patients continued to have ischemic chest pain at rest and were considered "medically refractory" by their referring physicians. A more aggressive medical regimen was used, and 54 patients (83\%) were rendered chest pain-free. Of the 11 truly refractory patients $(\mathbf{8 . 8 \%})$, coronary arteriography revealed an increased likelihood of left main or 3vessel disease (7 of 11 vs 26 of 114; $p=0.01$ ). Inhospltal treatment strategies for the 114 patients stabilized with medical therapy included continued medical therapy $(n=37)$, coronary angioplasty $(n=46)$ and bypass grafting $(n=31)$. The rate of myocardial infarction or death in patients managed medically was $3 \%$. Coronary angioplasty in medically stabllized patients was complicated by an abrupt closure rate of $26 \%$, and a $17 \%$ rate of myocardlal infarction, death or need for emergency bypass grafting. Medically stabilized patients undergoing bypass grafting had a $9 \%$ rate of myocardial infarction or death. Unstable angina truly refractory to current, maximal medical therapy is infrequent (8.8\%). However, the refractory group is vulnerable to adverse angioplasty results and cardlac events.

(Am J Cardiol 1992;70:577-581)

From the University of Michigan Medical Center, Ann Arbor, Michigan, and the Cleveland Clinic Foundation, Cleveland, Ohio. Manuscript received February 26, 1992; revised manuscript received May 15, 1992, and accepted May 18.

Address for reprints: Eric J. Topol, MD, Department of Cardiology F25, Cleveland Clinic Foundation, 9500 Euclid Avenue, Cleveland, Ohio 44195.
$\mathrm{U}$ Tnstable angina pectoris is responsible for $>750,000$ hospitalizations annually in the United States. ${ }^{1}$ With conventional antianginal therapy, up to $15 \%$ of patients develop myocardial infarction in the hospital. ${ }^{2}$ Recent studies suggest that routine use of intravenous heparin and aspirin significantly reduces morbidity and mortality in patients hospitalized with unstable angina. ${ }^{3,4}$ Urgent revascularization by coronary angioplasty or bypass grafting has an increased complication rate in patients with unstable angina pectoris. ${ }^{5,6}$ However, patients with unstable angina refractory to medical therapy are at high risk for in-hospital cardiac events and should be most strongly considered for urgent revascularization. The incidence and outcomes of refractory unstable angina in the contemporary setting of maximal antianginal, antiplatelet and anticoagulant therapy is unknown. We sought to define the incidence of refractory unstable angina in a group of patients with unstable angina transferred to our tertiary care facility for consideration of coronary revascularization.

\section{METHODS}

Selection of patients: Five hundred and two patients referred to the University of Michigan Hospital with the diagnosis of unstable angina between January 1, 1986 and January 1, 1991 were analyzed retrospectively. Patients were included in the study provided that they: (1) were transferred from an outside hospital after being admitted with chest pain at rest of $>20$ minutes duration; (2) had reversible electrocardiographic changes with chest pain, including $>1 \mathrm{~mm}$ ST-segment depression or elevation or T-wave inversion in 2 limb or contiguous precordial leads; (3) had peak creatine kinase levels $<2$ times the upper limits of normal; and (4) underwent an attempt at medical stabilization before transfer.

One hundred twenty-five patients fulfilled the inclusion criteria and constituted the study population (Figure 1). Baseline data abstracted from the clinical record on these patients included: (1) history of stable angina pectoris, myocardial infarction or congestive heart failure; (2) history of myocardial revascularization; (3) character and location of electrocardiographic changes with chest pain; (4) medical regimen at transfer; (5) maximal medical regimen at University of Michigan; (6) duration of medical therapy before resolution of chest pain or before patient was considered refractory; and (7) results of cardiac catheterization including coronary anatomy (stenoses considered significant if $\geq 70 \%$ ) and left ventricular ejection fraction.

Maximal medical therapy: Maximal medical therapy was considered treatment with a combination of as- 


\begin{tabular}{|c|c|c|c|}
\hline & $\begin{array}{c}\text { Refractory } \\
(n=11)\end{array}$ & $\begin{array}{l}\text { Medically } \\
\text { Stabilized } \\
(n=114)\end{array}$ & $p$ Value \\
\hline Age (year) & $68 \pm 10$ & $64 \pm 11$ & NS \\
\hline Male gender & $7(64 \%)$ & $61(54 \%)$ & NS \\
\hline Prior stable angina & $7(64 \%)$ & $83(73 \%)$ & NS \\
\hline Prior myocardial infarction & $4(36 \%)$ & $48(42 \%)$ & NS \\
\hline Prior coronary bypass surgery & $5(45 \%)$ & $20(18 \%)$ & 0.07 \\
\hline Ejection fraction (\%) & $43 \pm 13$ & $51 \pm 13$ & NS \\
\hline Duration of pain at rest (days) & $9 \pm 4$ & $4 \pm 4$ & 0.01 \\
\hline \multicolumn{4}{|l|}{ ST-segment changes } \\
\hline ST elevation & $2(18 \%)$ & $11(9 \%)$ & NS \\
\hline ST depression & $7(64 \%)$ & $42(37 \%)$ & NS \\
\hline T-wave inversion & $2(18 \%)$ & $61(54 \%)$ & 0.05 \\
\hline Anterior changes & $/(64 \%)$ & $25(22 \%)$ & 0.008 \\
\hline Inferior changes & 0 & $43(38 \%)$ & 0.03 \\
\hline Lateral changes & $4(36 \%)$ & $46(40 \%)$ & NS \\
\hline \multicolumn{4}{|l|}{ Coronary anatomy } \\
\hline Left main or 3-vessel disease & $7(64 \%)$ & $26(23 \%)$ & 0.01 \\
\hline 1- to 2-vessel disease & $4(36 \%)$ & $88(77 \%)$ & 0.01 \\
\hline $\begin{array}{l}\text { In-hospital death or myocardial } \\
\text { infarction }\end{array}$ & $4(36 \%)$ & $9(8 \%)$ & 0.009 \\
\hline
\end{tabular}

pirin, intravenous heparin, nitrates, $\beta$ blockers and calcium antagonists. The number of these agents a patient was receiving was noted. Patients were considered to have true refractory unstable angina if chest pain at rest continued despite treatment with all 5 classes of medication at maximal hemodynamically tolerated doses.

Patient groups: Patients were classified as medically refractory if chest pain and electrocardiographic

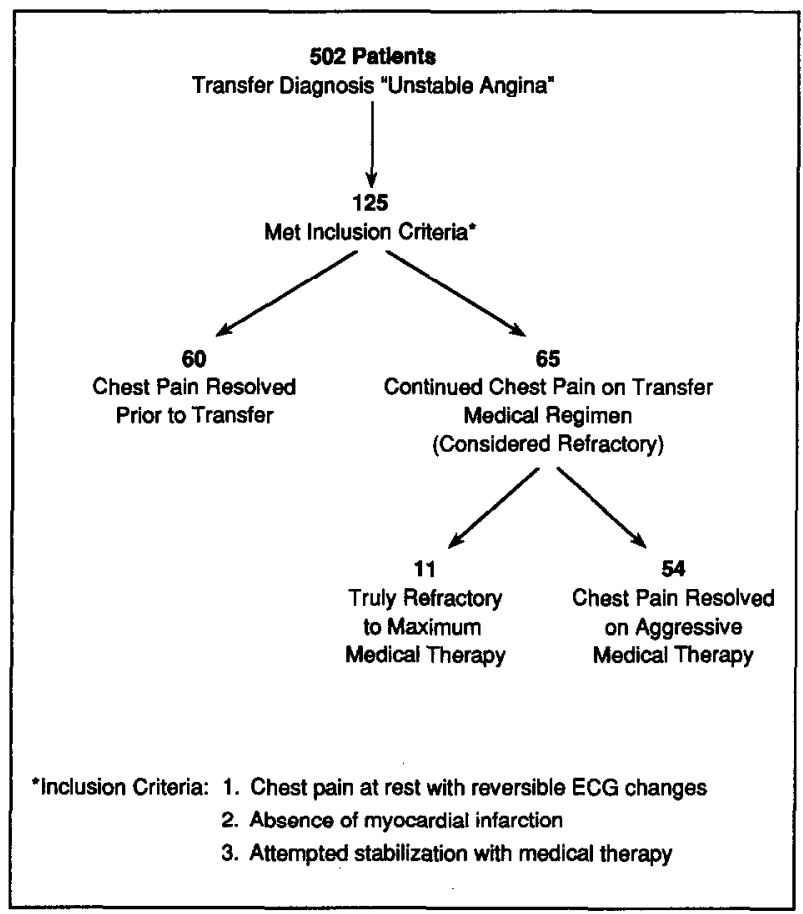

FIQURE 1. Outime of study population. Onby 11 of 125 patemts $(8.8 \%)$ with cheet paln at reat and reverithle electrocar. dographic (ECE) changes were rofrectory to maximal modical therapy, inchuting treatunent with aspinin, intravenous heparin, nitrates, calcium antagoniats and $\beta$ blockers. changes persisted with maximal medical therapy, or as medically stabilized if chest pain resolved with medical therapy. Medically stabilized patients were further classified based on subsequent in-hospital treatment strategy, which included continued medical therapy, coronary angioplasty and bypass grafting. In-hospital recurrent angina, myocardial infarction or death were recorded for each treatment strategy.

Statistical analysis: For discrete variables, analysis was performed with chi-square tests and for continuous variables, Student $t$ tests were used. All group data were expressed as mean $\pm 1 \mathrm{SD}$. A $\mathrm{p}$ value $<0.05$ was considered statistically significant.

\section{RESULTS}

In all, 502 patients with "unstable angina" were transferred to the University of Michigan Hospital during the study period (Figure 1). The following groups of patients were excluded from this cohort: 17 transferred directly for revascularization without attempts at medical stabilization; 28 with evidence of myocardial infarction; 51 without chest pain at rest; and 281 after review of the records did not document reversible electrocardiographic changes with chest pain. Inclusion criteria were fulfilled by 125 patients. Chest pain resolved with medical therapy in 60 of these patients before transfer. Chest pain at rest with ischemic electrocardiographic changes continued in 65 patients who were considered medically refractory by their referring physicians. A more aggressive medical regimen was used at the University of Michigan, and 54 (83\%) of these patients became free of chest pain. Only 11 patients $(8.8 \%)$ ultimately proved refractory to maximal medical therapy.

Demographic and clinical data: Table I shows characteristics of the 11 patients with refractory unstable angina compared with the 114 who stabilized with medical therapy. No significant differences were found between the groups regarding age, sex, history of stable angina pectoris or myocardial infarction, and left ventricular function. Patients with refractory unstable angina were more likely to have had prior coronary artery bypass grafting. Patients with refractory unstable angina had persistent chest pain despite an average of 9 days of maximal (5-drug) medical therapy, whereas those responding to medical therapy with resolution of chest pain did so in an average of 4 days $(p=0.01)$. Patients with refractory unstable angina were more likely to have anterior electrocardiographic changes with chest pain ( 7 of 11 vs 25 of $114 ; p=0.008$ ). Inferior electrocardiographic changes with chest pain were not seen in the refractory group $(p=0.03)$. T-wave inversion with chest pain was more often seen in patients who stabilized on medical therapy $(p=0.05)$. All patients underwent cardiac catheterization. Refractory patients had an increased likelihood of left main or 3-vessel coronary artery disease (7 of 11 vs 26 of 114 ; $\mathrm{p}=0.01$ ). A $>70 \%$ stenosis of the left main coronary artery was identified in 5 of 11 patients in the refractory group and in 2 of 114 in the medically stabilized group. In-hospital myocardial infarction or death was significantly more frequent in the refractory group ( 4 of 11 vs 9 of $114 ; p=0.009$ ). 


\begin{tabular}{|c|c|c|}
\hline & $\begin{array}{l}\text { Community } \\
\text { Hospitals } \\
(n=65)\end{array}$ & $\begin{array}{l}\text { University of } \\
\text { Michigan } \\
(n=65)\end{array}$ \\
\hline Aspirin & $46(71 \%)$ & $64(99 \%)$ \\
\hline Intravenous heparin & $21(32 \%)$ & $47(72 \%)$ \\
\hline Intravenous nitroglycerin & $15(23 \%)$ & $34(52 \%)$ \\
\hline Oral/topical nitrates & $40(62 \%)$ & $29(45 \%)$ \\
\hline Calcium antagonists & $53(82 \%)$ & $61(94 \%)$ \\
\hline$\beta$ blockers & $19(19 \%)$ & $34(52 \%)$ \\
\hline 1-drug therapy* & $6(9 \%)$ & 0 \\
\hline 2-drug therapy* & $16(25 \%)$ & $2(3 \%)$ \\
\hline 3-drug therapy* & $24(37 \%)$ & $13(20 \%)$ \\
\hline 4-drug therapy ${ }^{\star}$ & $12(18 \%)$ & $23(35 \%)$ \\
\hline 5-drug therapy* & $7(11 \%)$ & $27(42 \%)$ \\
\hline
\end{tabular}

Comparison of medical regimens: Table II compares the medical regimens at community hospitals and at the University of Michigan in the 65 patients considered to have medically refractory unstable angina at the time of transfer. Resolution of chest pain at the University of Michigan was achieved in 54 of 65 patients (83\%) with more frequent use of aspirin, and intravenous heparin and nitroglycerin. Multidrug therapy using combinations of aspirin, intravenous heparin, nitrates, calcium antagonists and $\beta$ blockers was also more frequent at the University of Michigan (50 of 65 patients [77\%] receiving 4- or 5-drug therapy vs 19 of $65[29 \%]$ at community hospitals; $p=0.0001$ ).

Hospital course (refractory unstable angina patients): All 11 patients with refractory unstable angina underwent revascularization. Coronary angioplasty was performed in 4 patients with refractory angina. One patient had abrupt closure and subsequent non-Q-wave myocardial infarction. One patient with a large dissection of the left anterior descending coronary artery died the day after angioplasty with a cardiac arrest. There were 7 refractory patients treated with bypass grafting. Two patients died after surgery; 1 could not be weaned from cardiopulmonary bypass, and 1 died 1 day after surgery from ventricular fibrillation. One patient had a perioperative myocardial infarction.

Hospital course (stabilized patients): The hospital course of the 114 medically stabilized patients included continued medical therapy in 37 , coronary angioplasty in 46, and bypass grafting in 31. Table III shows that the groups were similar in duration of medical therapy before resolution of chest pain, number of drugs used to achieve medical stabilization, and left ventricular function. Patients with left main or 3-vessel coronary artery disease were more likely to undergo bypass grafting during hospitalization, whereas those with 1- or 2-vessel coronary artery disease were more often treated with continued medical therapy or coronary angioplasty.

Table IV shows the hospital course of the 114 patients with unstable angina who became free of chest pain with medical therapy. Stabilized patients managed with continued medical therapy $(n=37)$ were chest
TABLE III Baseline Characteristics of 114 Patients with Unstable Angina Stabilized with Medical Therapy

\begin{tabular}{|c|c|c|c|}
\hline & \multicolumn{3}{|c|}{ In-Hospital Treatment Strategy } \\
\hline & $\begin{array}{c}\text { Medical } \\
\text { Management } \\
(n=37)\end{array}$ & $\begin{array}{l}\text { Angioplasty } \\
(n=46)\end{array}$ & $\begin{array}{c}\text { Bypass } \\
\text { Surgery } \\
(n=31)\end{array}$ \\
\hline $\begin{array}{l}\text { Days of medical therapy before } \\
\text { stabilization }\end{array}$ & 4 & 3 & 5 \\
\hline \multicolumn{4}{|l|}{$\begin{array}{l}\text { No. of drugs used at stabiliza- } \\
\text { tion* }\end{array}$} \\
\hline 1 to 3 & $17(46 \%)$ & $20(43 \%)$ & $13(42 \%)$ \\
\hline 4 or 5 & $20(54 \%)$ & $26(57 \%)$ & $18(58 \%)$ \\
\hline \multicolumn{4}{|l|}{ Coronary artery disease } \\
\hline 1- to 2-vessel & $30(81 \%)$ & $41(89 \%)$ & $13(42 \%)$ \\
\hline 3 -vessel or left main & $7(19 \%)$ & $5(9 \%)$ & $18(58 \%)$ \\
\hline Ejection fraction & $51 \pm 15$ & $53 \pm 19$ & $47 \pm 11$ \\
\hline Prior coronary bypass surgery & $9(24 \%)$ & $7(15 \%)$ & $3(10 \%)$ \\
\hline
\end{tabular}

\begin{tabular}{|c|c|c|c|}
\hline \multirow[b]{2}{*}{$\begin{array}{c}\text { Clinical } \\
\text { Outcomes }\end{array}$} & \multicolumn{3}{|c|}{ In-Hospital Treatment Strategy } \\
\hline & $\begin{array}{c}\text { Medical } \\
\text { Management } \\
(n=37)\end{array}$ & $\begin{array}{l}\text { Angioplasty } \\
(n=46)\end{array}$ & $\begin{array}{l}\text { Bypass Surgery } \\
\qquad(n=31)\end{array}$ \\
\hline Myocardial infarction & 0 & $4(9 \%)$ & $1(3 \%)$ \\
\hline $\begin{array}{l}\text { Death } \\
\text { No. of drugs at discharge* }\end{array}$ & $1(3 \%)$ & $1(2 \%)$ & $2(6 \%)$ \\
\hline 1 or 2 & $14(39 \%)$ & $21(47 \%)$ & $18(58 \%)$ \\
\hline 3 or 4 & $22(61 \%)$ & $24(53 \%)$ & $11(40 \%)$ \\
\hline
\end{tabular}

pain-free an average of 7 days before discharge. No patient in this group had a myocardial infarction and 1 (2.7\%) died during hospitalization. Recurrent stable angina developed in 3 patients $(8.1 \%)$ and was controlled by alterations in medical therapy.

Coronary angioplasty was performed in 46 medically stabilized patients before discharge. Indications for coronary angioplasty included: (1) coronary anatomy considered high risk for future cardiac events $(n=42$; $91 \%$ ); (2) ischemia on predischarge exercise testing $(\mathrm{n}=3 ; 6.7 \%)$; and $(3)$ recurrent exertional angina $(\mathrm{n}=1 ; 2.2 \%)$. Coronary angioplasty was performed an average of 6 days after the onset of unstable angina and 4 days after the last episode of chest pain. Angioplasty was successful in $92 \%$ of cases. Abrupt closure complicated 12 of 46 procedures (26\%). Emergency bypass grafting was needed in 3 patients $(6.5 \%), 4(8.7 \%)$ had postprocedural myocardial infarction, and $1(2.2 \%)$ died after angioplasty. After angioplasty, the incidence of emergency bypass grafting, myocardial infarction or death was $17 \%$.

Bypass grafting was performed in 31 medically stabilized patients before discharge. Indications for surgery included: (1) coronary anatomy considered high risk for future cardiac events $(n=26 ; 84 \%)$; (2) ischemia on predischarge exercise testing $(n=2 ; 6 \%)$; and (3) recurrent exertional angina $(n=3 ; 10 \%)$. One patient had a 
perioperative myocardial infarction, and there were 2 deaths after surgery.

Myocardial infarction or death occurred in $3 \%$ of patients managed medically, in $11 \%$ treated with coronary angioplasty and in $9 \%$ who underwent bypass grafting. Patients revascularized by coronary angioplasty or bypass grafting tended to be discharged with less medical therapy.

\section{DISCUSSION}

Atherosclerotic plaque rupture with concomitant platelet aggregation and thrombus formation is believed to be the underlying mechanism for the development of acute coronary syndromes. ${ }^{7,8}$ Most studies assessing morbidity and mortality in patients hospitalized with unstable angina were performed before routine use of intravenous heparin and aspirin. Conventional therapy of patients hospitalized with unstable angina with nitrates, $\beta$ blockers or calcium antagonists reduces the number of ischemic episodes, but does not reduce the frequency of myocardial infarction (13\%) or death (4\%). ${ }^{9-13}$ Both aspirin ${ }^{3,4,12,13}$ and intravenous heparin 3 3,4 have been shown to reduce the rate of myocardial infarction and death in patients hospitalized with unstable angina.

Our findings show that "true" refractory unstable angina is infrequent $(<9 \%)$ with aggressive contemporary medical therapy, including combinations of antianginal, anticoagulant and antiplatelet agents. Theroux et $\mathrm{al}^{3}$ showed a $23 \%$ incidence of refractory angina in patients hospitalized with resting or accelerating angina managed with nitrates, $\beta$ blockers or calcium antagonists. When intravenous heparin with or without aspirin was used, a $9.6 \%$ incidence of refractory angina was observed. Most patients in our study considered medically refractory at transfer were medically undertreated. Of patients considered medically refractory who were transferred to our hospital for urgent revascularization, most $(83 \%)$ became free of chest pain on a more aggressive medical regimen. Only one third of these pseudorefractory patients were receiving intravenous heparin, and surprisingly, 30\% were not receiving aspirin therapy.

Persistence of chest pain in patients hospitalized with unstable angina despite maximal medical therapy predicts a poor outcome, with a $51 \%$ incidence of early infarction or death. ${ }^{14}$ All refractory patients in this study underwent revascularization by either coronary angioplasty or bypass grafting. However, a $36 \%$ rate of in-hospital myocardial infarction or death was still observed.

The hospital treatment strategies for medically stabilized patients included continued medical management, coronary angioplasty and bypass grafting. Several prior studies showed that patients with unstable angina who become chest pain-free with medical therapy have a low rate of in-hospital cardiac events, with a 1 to $2 \%$ mortality rate and a 7 to $9 \%$ rate of myocardial infarction. ${ }^{14,15}$ In the study by Theroux et $\mathrm{al}^{3}$ and the Research Group on Instability in Coronary Artery Disease in Southeast Sweden (RISC) trial, ${ }^{4}$ the use of intravenous heparin and aspirin in combination with antiangi- nal therapy in the treatment of patients hospitalized with unstable angina resulted in a $1.5 \%$ rate of myocardial infarction or death. Medically stabilized patients in our study whose treatment strategy consisted of continued medical therapy had a low rate $(30 \%)$ of in-hospital myocardial infarction or death. Rapid progression of the underlying coronary stenosis is known to occur in most patients after an episode of unstable angina, with 30 to $50 \%$ redeveloping angina and crossing over to revascularization by 1 year. ${ }^{16}$ Frequently cited predictors of poor long-term outcome in patients with unstable angina managed medically include left main or 3-vessel coronary artery disease, decreased left ventricular function, abnormal baseline electrocardiogram, prior myocardial infarction, reperfusion abnormality on thallium imaging, and silent ischemia on continuous ambulatory monitoring. ${ }^{17-20}$ Thus, although most patients hospitalized with unstable angina do not need urgent revascularization for relief of chest pain, recurrent anginal symptoms after discharge are common.

Coronary angioplasty within the first 1 to 2 weeks after the onset of unstable angina has an increased complication rate. . $^{5,16,21-26}$ Angioplasty in this setting of intraluminal thrombus ${ }^{27}$ carries a significantly higher rate of abrupt closure. ${ }^{28} \mathrm{~A}$ review of the studies of coronary angioplasty in unstable angina shows a major complication rate (myocardial infarction, emergent bypass grafting or death) of 10 to $26 \% .^{5,16,21-26}$ Treatment of these patients with 3 to 5 days of intravenous heparin in preparation for coronary angioplasty may decrease this complication rate. ${ }^{29,30}$ Myler et $\mathrm{al}^{5}$ found that angioplasty in patients within the first 2 weeks after the onset of unstable angina is associated with a lower initial success rate and a two- to threefold increased risk for myocardial infarction, need for emergency bypass grafting, death or development of late recurrent angina. The high complication rate and poor outcome for coronary angioplasty in patients with unstable angina in our study (26\% abrupt closure rate, and $17 \%$ incidence of myocardial infarction, emergency bypass grafting or death) supports the contention that early coronary angioplasty in unstable angina has a complication event rate that may exceed the natural history of adverse cardiac events occurring in this population when managed conservatively with medical therapy. ${ }^{23}$ An increased operative mortality has also been reported when coronary artery bypass grafting is performed in patients with unstable angina. ${ }^{6}$ The rate of myocardial infarction or death in this study for medically stabilized patients undergoing bypass grafting before hospital discharge was $9 \%$.

Comparisons between treatment strategies (medical management, coronary angioplasty and bypass grafting) of the medically stabilized patients are not possible, because of the retrospective nature of this study. Because our hospital serves as a referral center, the characteristics of patients with unstable angina in this study may differ from those presenting to other hospitals. Furthermore, with the inclusion criteria selecting only patients with prolonged angina at rest and electrocardiographic changes, the high complication rate of coronary angioplasty may not reflect the results of angioplasty in patients with new-onset or accelerating unsta- 
ble angina pectoris. Finally, the data are limited by the absence of long-term follow-up and thus only provide a "window" of the acute phase of this clinical syndrome.

\section{REFERENCES}

1. National Center for Health Statistics: Vital and Health Statistics: Detailed Diagnosis and Procedures for Patients Discharged From Short Stay Hospitals. US Department of Health and Human Services, Public Health Service, Series B No. 90, Hyattsville, Maryland, 1987.

2. Julian DG. The natural history of unstable angina. In: Hugenholtz PG, Goldman BS. Unstable Angina: Current Concepts and Management. Stuttgart, Schattauer, 1985:65-70.

3. Theroux P, Ouimet H, McCans J, Latour JG, Joly P, Levy G, Pelletier E, Juneau M, Stasiak J, DeGuise P. Aspirin, heparin, or both to treat acute unstable angina. $N$ Engl J Med 1988;319:1 105-1111.

4. The RISC Group. Risk of myocardial infarction and death during treatment with low dose aspirin and intravenous heparin in men with unstable coronary artery disease. Lancet 1990;336:827-830.

5. Myler RK, Shaw RE, Stertzer SH, Bashour TT, Ryan C, Hecht HS. Unstable angina and coronary angioplasty. Circulation 1990;82(suppl II):II-88 -II-95.

6. Pansi AF, Khon S, Deupree RH, Sharma GU, Scott SM, Luchi RJ. Medical compared with surgical management of unstable angina: 5-year mortality and morbidity in the Veterans Administration Study. Circulation 1989;80: 1176-1189.

7. Falk E. Unstable angina with fatal outcome: dynamic coronary thrombosis leading to infarction and/or sudden death: autopsy evidence of recurrent mural thrombosis with peripheral embolization culminating in total vascular occlusion. Circulation 1985;71:699-708.

8. Davies $M$, Thomas A. Plaque fissuring: the cause of acute myocardial infarction, sudden ischemic death, and crescendo angina. Br Heart $J$ 1985;53:63-73. 9. Curfman GD, Heinsimer JA, Lozner EC, Fung HL. Intravenous nitroglycerin in the treatment of spontaneous angina pectoris: a prospective, randomized trial. Circulation 1983;67:276 281.

10. Holland Intrauniversity Nifedipine/Metoprolol Trial (HINT) research group. Early treatment of unstable angina in the coronary care unit: a randomized, double-blind, placebo controlled comparison of recurrent ischemia in patients treated with nifedipine or metoprolol or both. Br Heart J 1986;56:400-413. 11. Gottlieb SO, Weisfeldt MD, Ouyang P. Effect of the addition of propranol to therapy with nifedipine for unstable angina pectoris: a randomized double-blind placebo-controlled trial. Circulation 1986;73:331-337.

12. Cairns JA, Gent M, Singer J, Finnie KJ, Froggatt GM, Holder DA, Jablonsky G, Kostuk WJ, Melendez LJ, Myers MG. Aspirin, sulfinpyrazone, or both in unstable angina. $N$ Engl $J$ Med 1985;313:1369-1375.

13. Lewis HD, Davis JW, Archibald DG, Steinke WE, Smitherman TC, Doherty JE, Schnaper HW, LeWinter MM, Linares E, Pouget JM, Sabharwal SC, Chesler E, DeMots $H$. Protective effects of aspirin against acute myocardial infarction and death in men with unstable angina: results of a Veterans Administration cooperative study. $N$ Engl J Med 1983;309:396-403.

14. Gazes PC, Mobley EM, Favis HM, Duncan RC, Humphries GB. Preinfarctional (unstable) angina: a prospective study - ten year follow-up. Circulation $1973 ; 48: 331-337$
15. Severi S, Michelassi C, Orsini E, Marraccini P, L'Abbate A. Long term prognosis of transient acute myocardial ischemia at rest. $\mathrm{Am} J$ Cardiol 1989;64:889-895.

16. DeFeyter PJ, Serruys PW. Percutaneous transluminal coronary angioplasty for unstable angina. In: Topol EJ, ed. Textbook of Interventional Cardiology. WB Saunders, 1990:254-265.

17. Marmur JD, Freeman MR, Langer A, Armstrong PW. Prognosis in medically stabilized unstable angina: early Holter ST-segment monitoring compared with predischarge exercise thallium tomography. Ann Intern Med 1990;113:575-579. 18. Uthurralt N, Davies GJ, Parods $O$, Benciuelli W, Maseri A. Comparative study of myocardial ischemia during angina at rest and on exertion using thallium201 scintigraphy. Am J Cardiol 1981;48:410-417.

19. Swahn E, Areskog M, Berglund U, Walfridsson H, Wallentin L. Predictive importance of clinical findings and a predischarge exercise test in patients with suspected unstable coronary artery disease. Am J Cardiol 1987;59:208-214.

20. DeServi S, Berzuini C, Poma E, Ferrario M, Ghio S, Scire A, Cioffi P, Ardissino D, Montemartini C, Specchia G. Long-term survival and risk stratification in patients with angina at rest undergoing medical treatment. Int $J$ Cardiol $1989 ; 22: 43-50$

21. Schieman G, Cohen B, Kozina J. Intracoronary urokinase for intracoronary thrombus accumulation complicating percutaneous transluminal coronary angioplasty in acute ischemic syndromes. Circulation 1990;82:2052-2060.

22. Dorros G, Cowley M, Simpson J, Bentivoglio LG, Block PC, Bourassa M, Detre K, Gossclin AJ, Gruntzig AR, Kelscy SF, Kent KM, Mock MB, Mullin SM, Myler RK, Passamani ER, Stertzer SH. Percutaneous transluminal coronary angioplasty: report of complications from National Heart, Lung, and Blood Institute PTCA registry. Circulation 1983;67:723-730

23. De Feyter PJ, Suryapranata H, Serruys PW, Beatt K, van Domburg R, van den Brand M, Tijssen JJ, Azar AJ, Hugenholtz PG. Coronary angioplasty for unstable angina: immediate and late results in 200 consecutive patients with identification of risk factors for unfavorable early and late outcome. $J$ Am Coll Cardiol 1988; 12:324-333.

24. Deligonul U, Gabliani G, Caralis D, Kern M, Vandornael M. Percutaneous transluminal coronary angioplasty in patients with intracoronary thrombus. $\mathrm{Am} \mathrm{J}$ Cardiol 1988;62:474-476.

25. Sugrue DD, Holmes DR, Smith HC, Reeder GS, Lane GE, Vlietstra RE, Bresnahan JF, Hammes LN, Piehler JM. Coronary artery thrombus as a risk factor for acute vessel occlusion during percutaneous transluminal coronary angioplasty: improving results. Br Heart $J$ 1986;56:62-66.

26. Cameron $J$, Buchbinder $M$, Wexler $L$, Oesterle $S$. Thromboembolic complications of percutaneous transluminal coronary angioplasty for myocardial infarction. Cathet Cardiowasc Diagn 1987;13:100-106.

27. Bresnahan DR, Davis JL, Holmes DR, Smith HC. Angiographic occurrence and clinical correlates of intraluminal coronary artery thrombus: role of unstable angina. J Am Coll Cardiol 1985;60:285-289.

28. Mabin TA, Holmes DR, Smith HC. Intracoronary thrombus: role in coronary occlusion complicating percutaneous transluminal coronary angioplasty. $J$ Am Coll Cardiol 1985;5:198-202.

29. Laskey M, Deutsch E, Hirshfeld J, Kussmaul W, Barnathan E, Laskey W. Influence of heparin therapy of percutaneous transluminal coronary angioplasty outcome in patients with coronary arterial thrombus. Am J Cardiol 1990;65: 179-182.

30. I askey $M$, Deutsch $E$, Barnathan $E$, Laskey $W$. Influence of heparin therapy on percutaneous transluminal coronary angioplasty outcome in unstable angina pectoris. Am J Cardiol 1990;65:1425-1429. 